\title{
Computer-assisted analysis of conversation
}

\author{
AMY HERSTEIN GERVASIO \\ Hamilton College, Clinton, New York
}

\begin{abstract}
Psychologists and linguists have employed computer programs to analyze written and spoken text. The Computer-Assisted Language Analysis System (CALAS) is a computer program that utilizes three sequential programs to parse the language of two speakers in a conversation into words, phrases, and clauses, and places verbs and nouns into categories derived from theories of case grammar. Rather than using a large "dictionary." CALAS determines the category of each word on the basis of adjacent function words and placement of the words in the sentence. Output from CALAS lists the frequency of each category and can be used to construct measures of linguistic style and verb usage. Research employing CALAS includes the study of various types of psychotherapy, behavior therapy, classroom discourse, and literary texts.
\end{abstract}

The major method for studying written and spoken language has been content analysis, a process whereby nominal data are divided into units, categorized, and counted. Researchers engaged in such analysis make inferences from a text about some characteristic of its speaker that is not directly observable (Kiesler, 1973). Recent content analysis of conversation in interactions such as psychotherapy have used categories of grammar to provide a framework for studying the natural language used in human relationships. By using grammatical categories rather than abstract categories derived from one particular psychological theory, researchers can devise measures of natural language that can be applied across a variety of theoretical orientations (Meara, Shannon, \& Pepinsky, 1979). Several content analysis systems based on grammatical categories employ com. puters to analyze the text of conversation.

This article (1) presents a brief overview of different computer programs used to analyze text, (2) focuses on the Computer-Assisted Language Analysis System, or CALAS (Rush, Pepinsky, Meara, Landry, Strong, Valley, \& Young, 1974), and (3) describes how CALAS has been employed in research in psychotherapy, education, and linguistics.

\section{COMPUTERIZED SYSTEMS FOR ANALYZING LANGUAGE}

The General Inquirer (Stone, Bales, Namenwirth, \& Ogilvie, 1962) was one of the first computer systems to be used in the content analysis of psychotherapy. Harway and Iker (1964) and Starkweather and Decker (1964) also developed computerized programs that analyzed the frequency of the association of words in psychoanalytic sessions. These programs matched words

I would like to thank Jonathan Vaughan for his helpful comments on the first draft of this paper. Requests for reprints should be sent to Amy Herstein Gervasio, Department of Psychology, Hamilton College, Clinton, NY 13323. used in therapy to those in the computer's dictionary. The drawbacks of these programs were that they required constant updating of the dictionary and that the aggregation of words into abstract categories required considerable a priori judgment, particularly when polysemous words appeared (May, 1977).

Winograd (1972) devised a set of computer programs and an algorithm for the analysis of natural language used during problem solving. His system used a knowledge base represented by rules of procedures rather than by tables or dictionaries of words. Clippinger (1977) expanded Winograd's transformational rules to develop a computer program that generated discourse resembling free association in psychoanalysis. Clippinger was more interested in modeling a "neurotic belief system" that would produce a style of language found in free association than he was in analyzing language per se.

The Syntactic Language Computer Analysis System, or SLCA-III (Cummings \& Renshaw, 1979), is another system using programs that incorporate Winograd's (1972) methods. Cummings and Renshaw (1979) contended that language as behavior is interdependent with perception and cognition. They proposed that parts of speech may correspond to the "perceptual propositions of experience." These propositions include knowledge about perception, sensation, and social relationships. The SLCA-III defines informational units of perception (nouns) and relations between these units (verbs), as well as the quantity and quality of both informational and relational units (adjectives and adverbs). Cummings and Renshaw identified eight classes of variables of perception accounted for in language: social perception, sensation, existence, motion, disposition, time, symmetry, and conditionality. Their computer programs classified words in a text into these categories, and computed the frequency or "density" of each category in the text. They described several studies associating differences in the density of many SLCA-III variables with differences in age, sex, dogmatism, Machiavellianism, and other personality measures. 


\section{CALAS AND CASE GRAMMAR}

The Computer-Assisted Language Analysis System (CALAS), developed at The Ohio State University by Rush et al. (1974), is similar in principle to the SLCA-III. The rules for analyzing language are derived from a semantically based conception of grammar called case grammar. As synthesized by Cook (1979) from the work of Chafe (1970), Fillmore (1968), and others, the focus of case grammar is on the inherent relationships between verb phrases and noun phrases and the roles they play in conveying the meaning of a sentence. For Chafe and for Cook, the verb is the focal point of an utterance; it tells the listener how named things (nouns) are to be taken. In psychological terms, "the verb is the name for various states, conditions, experiences, possessions, or actions that assert something about the things named and related to it" (Bieber, Patton, \& Fuhriman, 1977, p. 265).

Cook (1979) presented a case grammar matrix in which he defined three basic types of verbs: stative, action, and process. (Examples of these verb types are presented in Table 1.) As summarized by Gervasio, Pepinsky, and Schwebel (1983) and Meara, Pepinsky, Shannon, and Murray (1981), stative verbs describe a noncausal relationship between persons or things, or a state or property of a person or thing (e.g., "to be"). Action verbs describe a causal relationship between persons or things, with the specification of an agent that makes something happen (e.g., "make," "hit"). Finally, process verbs describe a causal relationship without the specification of an agent in which something is happening to a person or thing (e.g., "tire," "sleep").

The three basic types of verbs can be divided into subtypes by considering the inherent relationships that certain verbs have to nouns that habitually precede them. (The role that a noun takes in relation to the verb is called a "case.") There are two cases: benefactive and experiential (Cook, 1979). Experiential verbs (i.e., verbs that necessitate experiential nouns) describe feeling, sensing, and knowing, with the assumption that there is a person who experiences. For the purposes of research in psychological or emotional states, stativeexperiencer verbs have sometimes been divided into two categories: experience-affective (SEA) verbs, such as "like," "feel," and "want"; and experience-cognitive (SEC) verbs, such as "think," "doubt," and "guess" (May, 1977). Benefactive verbs describe states, actions,

Table 1

Examples of Verb Types

\begin{tabular}{clll}
\hline Type & Basic & Experiencer & Benefactive \\
\hline \multirow{2}{*}{ Stative } & would & forget (SEC) & own \\
& are being & fear (SEA) & have \\
Action & work & mention & send \\
& do & talk & protect \\
& tire & look & found \\
Process & live & hear & lost \\
\hline
\end{tabular}

or processes in which someone or something is a beneficiary (e.g., "owe," "give," "have").

CALAS is based on a modification of Cook's (1979) case grammar matrix. Programs are written in two computer languages, SPITBOL and PL/I, and can be used with any computer system that is IBM compatible. Originally designed to run with punch cards as a "batch job," CALAS has been adapted for on-line use by employing a series of programs that interface with an IBM 370/3031 computer and the DEC 10 for data file storage. TSO and WYLBUR are two on-line textprocessing systems that have been used to prepare the data and run the CALAS programs. CALAS programs are currently being rewritten in Pascal (H. B. Pepinsky, personal communication, August 27, 1983).

\section{Preparation of Text}

A transcript of spoken interaction, coded by speaker, is prepared in dialogue form. Each line of text is typed on-line or on punch cards as it appears in English. Only slight modifications from the original are necessary; for example, verbs in a question must be inverted.

A sequence of three programs analyzes the text: Eyeball, Phraser, and Clause/Case. Human editing is done after the completion of each program to provide more accurate input for the next program. The amount of editing necessary decreases with each program.

\section{Eyeball}

Written in SPITBOL, Eyeball analyzes the text one sentence at a time. (In spoken text, the concept of a sentence is ambiguous because punctuation is ultimately arbitrary; "blocks of clauses" is a more appropriate term.) Each word in a sentence is assigned a grammatical category, such as noun, verb, adverb, etc. Eyeball uses accepted rules of English grammar (Patton \& Meara, 1983). However, the grammatical class assigned to each word is based upon the surrounding "function" words such as prepositions, articles, and auxiliary verbs-words such as "to," "a," and "have." By basing assignment on the position of words in a sentence, CALAS needs only a small dictionary of about 600 words (Patton \& Meara, 1983). Words can be added to the dictionary if necessary.

An example of how Eyeball assigns categories is presented in Table 2. The sample sentence is taken from data collected in a study by Gervasio et al. (1983), and is one complete "turn" in a longer conversation. It reads, "Look, I pay the bills, and I want to see you." In its first pass over the text, Eyeball identifies function words in a linear fashion. The word "I" is labeled as a noun, "the" is labeled as a determiner, and so on. In English, a word following a noun and preceding a determiner can only be a verb. Therefore, in the second pass over the text, Eyeball can identify items in the rest of the sentence based upon the position of the words. In the example, Eyeball is not sure whether "look" is a verb describing sight or is an idiomatic expression. On the printout, it 
Table 2

Output From Eyeball

Text

Look. I pay the bills, and I want to see you.

Eyeball (first pass)

LOOK, I PAY THE BILLS, AND I WANT TO SEE YOU.

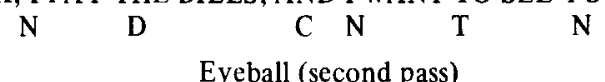

Eyeball (second pass)

LOOK, I PAY THE BILLS, AND I WANT TO SEE YOU.

$\begin{array}{lllllllllllll}E & \text { N } & N & V & D & N & C & N & V & T & F & N\end{array}$

Note $-N=$ noun; $D=$ determiner $C=$ conjunction; $T=$ "to" part of infinitive; $V=$ verb; $F=$ verb part of infinitive; $E=e x$ pletive.

Table 3

Output From Phraser

\begin{tabular}{l}
\hline \multicolumn{3}{c}{ Phraser } \\
\hline LOOK /, / I / PAY / THE BILLS /, / AND / I / WANT / TO \\
E N N V C N C C N V \\
SEE / YOU. \\
V N N
\end{tabular}

Note $-E=$ expletile $;=$ noun phrase; $V=$ verb phrase $C=$ conjunction.

presents both choices to the human editor, who decides that in this case "look" is an idiomatic expression. The choice is made using a program called Editeye.

\section{Phraser}

The edited output from Editeye serves as an input for Phraser. Phraser, which is written in PL/I, uses the class assignments from Eyeball to classify the text into noun, verb, adverbial, and prepositional phrases (Patton \& Meara, 1983). Phraser uses approximately 65 transformational rules. (The output from Phraser is presented in Table 3.) If necessary, Phraser can be corrected using a program called Editphraser. In the example, the words "the bills" are classified as a noun phrase.

\section{Clause/Case}

Output from Editphraser is submitted to Clause/ Case. Here the phrases are grouped into main and sub-

Table 4

Modified Computer Printout of Clause/Case

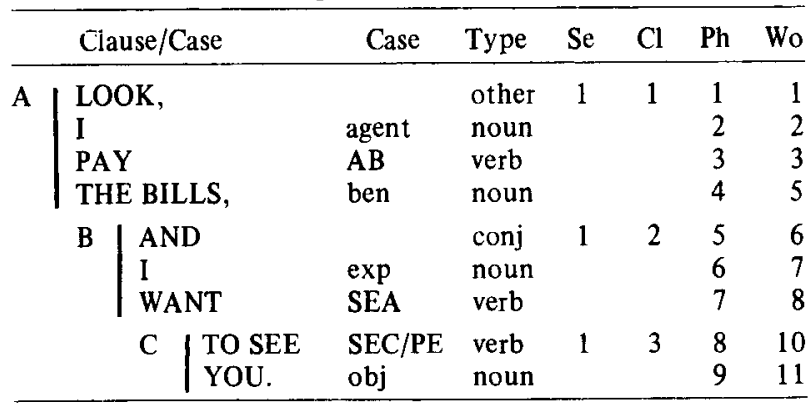

Note-agent $=$ agentive case; $A B=$ action-benefactive verb $;$ ben $=$ benefactive case; $\exp =$ experiencer case; SEA = stative-experi . encer-affective verb; $S E C=$ stative-experiencer-cognitive verb; $P E=$ process-experiencer verb; obj $=$ objective case. $S e=$ sentence; $\mathrm{Cl}=$ clause $; \mathrm{Ph}=$ phrase $;$ Wo $=$ word. ordinate clauses. (A clause is a unit of information containing only one verb.) Noun phrases in the clause are given case grammar labels, such as agent, experiencer, or benefactor. Verbs are classified into the categories discussed earlier and presented in Table 1. The output also displays cumulative totals for the number of sentences, clauses, phrases, and words for each speaker and for the entire text. (A modified version of the output from Clause/Case for the sample sentence is presented in Table 4.) The program presents each clause in a vertical display. Note that the noun "I" is assigned a different case role in the two clauses in which it appears. In the first clause, "I" represents a noun that is an agent of an action-benefactive verb. In the third clause, "I" represents a noun that experiences a stative-experienceraffective verb.

Clause/Case also presents a choice of verb assignments for the verb "to see." It suggests that "see" may serve as a stative-experiencer-cognitive verb meaning "I know" or that it may be a process-experiencer verb dealing with vision. The human editor decides that the context of the sentence indicates the choice of the latter label. This change can be made with Editclause.

\section{STYLISTIC MEASURES}

The frequency counts in Clause/Case can be used to form several measures of style. Cook (1979) proposed two measures of "stylistic complexity" that use the clause as the basic structural unit of discourse. Average block length $(\mathrm{ABL})$ is a measure of the amount of information contained in a text; it is calculated by dividing the total number of clauses by the number of main clauses. Average clause depth (ACD) is a measure of the level of clause embeddedness in the information blocks. It is calculated by assigning the main clause a value of 1 , the next subordinate clause a value of 2 , and so on. The sum of the values is divided by the number of clauses. In the sample sentence, the speaker has used two subordinate clauses and one main clause. $\mathrm{ABL}$ for the sample equals 3.0, and $\mathrm{ACD}$ equals 2.0 . Compared with Cook's sample of literary texts, the sentence would fall into the moderately complex range. (It should be noted that the sentence analyzed here was one of eight sentences uttered by the speaker, and that the $\mathrm{ABL}$ and $\mathrm{ACD}$ of the entire text were much lower than 3.0.)

CALAS can be used to generate other measures of style or verb usage, such as length of sentences, ratio of noun phrases to verb phrases, and number of specific cases (Hurndon, Pepinsky, \& Meara, 1979). (Table 5 presents a list of representative stylistic measures. The measures chosen depend upon the hypotheses of the experiment. For example, in a study of the use of "feeling language" in Rogerian psychotherapy, a relevant measure might be the client's proportion of SEA verbs to total verbs. In a study of the stylistic complexity of language used in assertion training, a relevant measure might be the ABL (Gervasio et al., 1983). 
Table 5

Stylistic Measures

\begin{tabular}{ll}
\hline \multicolumn{1}{c}{ Variable } & \multicolumn{1}{c}{ Definition } \\
\hline $\begin{array}{c}\text { Average Block } \\
\text { Length }\end{array}$ & $\begin{array}{l}\text { Number of clauses divided by number of } \\
\text { main clauses }\end{array}$ \\
$\begin{array}{c}\text { Average Clause } \\
\text { Depth }\end{array}$ & $\begin{array}{l}\text { Sum of weighted embedded clauses } \\
\text { divided by the number of clauses }\end{array}$ \\
$\begin{array}{c}\text { Average Essential } \\
\text { Cases }\end{array}$ & $\begin{array}{l}\text { Number of noun phrases divided by the } \\
\text { number of clauses }\end{array}$ \\
Phrases per Main & $\begin{array}{l}\text { Number of phrases divided by the } \\
\text { Clause }\end{array}$ \\
Words per & $\begin{array}{l}\text { Number of main clauses } \\
\text { of turns per speaker }\end{array}$ \\
Turn & Total number of words \\
Words & Total number of phrases \\
Phrases & Total number of clauses \\
Clauses &
\end{tabular}

\section{RESEARCH UTILIZING CALAS}

CALAS has been used to study the structure of conversation taking place in psychotherapy and classroom situations, as well as the style of test manuals and literary texts. Bieber et al. (1977) found that a client's verb usage began to parallel that of the therapist over the course of 25 counseling sessions. Meara et al. (1979) demonstrated that the linguistic styles of Carl Rogers, Fritz Perls, and Albert Ellis differed significantly from each other. Gervasio et al. (1983) found that verb usage in assertive and passive speech is significantly different, but that the stylistic complexity of both types of speech differ from levels predicted by much of the assertion literature. Pepinsky and DeStefano (in press) used CALAS to study the changes in patterns of interaction between a teacher and students of different ethnic backgrounds in a first-grade classroom over the course of 1 year. Hurndon et al. (1979) showed that measures of stylistic complexity account for most of the variance in "conceptual level" as measured by the Paragraph Completion Method.

In summary, computer-assisted linguistic analysis can provide psychologists and linguists with a method for studying conversation, patterns of interaction, and the subtleties and ambiguities inherent in language.

\section{REFERENCES}

Bieger, M. R., Patton, M. J., \& Fuhriman, A. J. (1977). Metalanguage analysis of counselor and client verb usage in counseling. Journal of Counseling Psychology, 24, 264-271. Chafe, W. I. (1970). Meaning and the structure of language. Chicago: University of Chicago Press.

Clippingen, J. H. (1977). Meaning and discourse: A computer model of psychoanalytic speech and cognition. Baltimore: Johns Hopkins University Press.

Coox, W. A. (1979). Case grammar: Development of the matrix model (1970-1978). Washington, DC: Georgetown University Press.

Cummings, H. W., \& Renshaw, S. L. (1979). SLCA-III: A metatheoretic approach to the study of language. Human Communication Research, 5, 291-300.

Fillmore, C. (1968). The case for case. In E. Bach \& K. T. Harms (Eds.). Universals in linguistic theory. New York: Holt, Rinehart \& Winston.

Gervasio, A. H., Pepinsky, H. B., \& Schwebel, A. I. (1983). Stylistic complexity and verb usage in assertive and passive speech. Journal of Counseling Psychology, 30, 546-556.

HaRway, N. I., \& IKER, H. D. (1964). Computer analysis of content in psychotherapy. Psychological Reports, 4, 720-722.

Hurndon, C. J., Pepinsxy, H. B., \& Menra, N. M. (1979). Conceptual level and structural complexity in language. Journal of Counseling Psychology, 26, 190-197.

Kissler, D. J. (1973). The process of psychotherapy. Chicago: Aldine.

MAY, G. (1977, May). Psychotherapy and language: Linguistic convergence between therapist and client. Unpublished doctoral dissertation, Ohio State University. (University Microfilms No. 77-24, 664)

Meara, N. M., Pepingxy, H. B., Shannon, J. W., \& Murray, W. A. (1981). A comparison of semantic communication in and expectations for counseling across three theoretical orientations. Journal of Counseling Psychology, 28, 110-118.

Meara, N. M., Shannon, J. W., \& Pepinsky, H. B. (1979). Comparison of stylistic complexity of the language of counselor and client across three theoretical orientations. Journal of Counseling Psychology, 26, 181-189.

Patron, M. J., \& MEara, N. M. (1983). The analysis of natural language in psychological treatment. In R. J. Russell (Ed.), Spoken interaction in psychotherapy. New York: Irvington.

Pepinsky, H. B., \& DeSterano, J. S. (in press). Interactive discourse in the classroom as organizational behavior. In B. A. Hutson (Ed.), Advances in reading/language research. Greenwich, CT: JAI Press.

Rugh, J. E., Pepingky, H. B., Meara, N. M., Landry, B. C., Strong, S. M., Valley, J. A., \& Youno, C. E. (1974). A Computer-Assisted Language Analysis System (OSU-CISRCTR-73-9). Columbus: Ohio State University, Computer and Information Science Research Center.

Starkweather, J. A., \& Decker, J. B. (1964). Computer analysis of interview content. Psychological Reports, 15, 875-882.

Stone, P. J., Bales, R. F., Namenwirth, A., \& Ooilvie, D. M. (1962). The General Inquirer: A computer system for content analysis and retrieval based on the sentence as a unit of information. Behavioral Science, 7, 484-497.

Winoorad, T. (1972). Understanding natural language. New York: Academic Press. 